\title{
Hardness and Structure of Ausformed Fe-Ni and Fe-Ni-C Alloys*
}

\author{
By Imao Tamura**, Hirofumi Yoshimura***, Masao Ibaraki** \\ and Masayoshi Tagaya****
}

\begin{abstract}
The effects of ausforming on the hardness and structure of $\mathrm{Fe}-\mathrm{Ni}$ and $\mathrm{Fe}-\mathrm{Ni}-\mathrm{C}$ alloys were examined. The results of microhardness tests showed that some amount of the carbon content might be essential for the strengthening of steel by ausforming. Optical micrographs showed that a martensite plate in the ausformed specimen was finer than that in the unausformed, and was bent and kinked. Transmission electron micrographs and electron diffraction patterns of ausformed $\mathrm{Fe}-\mathrm{Ni}-\mathrm{C}$ alloy showed that : (1) There were strong stresses within and around the martensite plate. (2) The twin faults in the martensite crystal were also recognized. (3) A cloudy distribution of dislocations was observed in the martensite plate, and the carbon atoms might migrate on these dislocations. The ausformed specimen was hardened mainly by precipitation and/or dispersion of carbides. (4) Severely kinked martensite plates were frequently observed. (5) The lattice orientation relationship between austenite and martensite in the ausformed $\mathrm{Fe}-\mathrm{Ni}-\mathrm{C}$ alloy approximately obeyed the usual law in the same way as in the unausformed.

(Received October 25, 1963)
\end{abstract}

\section{Introduction}

When a steel is deformed at a metastable austenitic state, transformed into martensite and then tempered, the steel is much more strengthened than an ordinarily quenched and tempered steel. Since such a phenomenon was discovered by Harvey ${ }^{(1)}$ in 1951, it has been investigated and developed by several researchers $^{(2)-(16)}$, and such a thermal-mechanical treatment

* This paper was published originally in Japanese in the Journal of Japan Institute of Metals, 27 (1963), No. 5, 206 and a part of this paper was reported in Memoirs of the Institute of Scientific and Industrial Research, Osaka Univ., 19 (1962), 67, as a summary in English.

*** The Institute of Scientific and Industrial Research, Osaka University, Sakai, Osaka.

*** Graduate Student at the Institute of Scientific and Industrial Research, Osaka University, Sakai, Osaka.

***** Faculty of Engineering, Osaka University, Miyakojima, Osaka.

(1) R. F. Harvey: Iron Age, 168 (1951), Dec. 27, 70.

(2) E. M. H. Lips and H. Van Zuilen: Metal Progr., 66 (1954), Aug., 103.

(3) G. R. Rish and H. O'Neill : J. Iron Steel Inst., 173 (1953), 398.

Trans. J I M is called "Ausforming".

But, the reason for the strengthening of steel by ausforming has not been fully clarified yet, and many

(4) P.R. V. Evans and H. O'Neill: J. Iron Steel Inst., 191(1959) 34.

(5) D. J. Schmatz and V. F. Zackay: Trans. ASM, 51 (1959), 476

(6) J. C. Shyne, V. F. Zackay and D. J. Schmatz: Trans. ASM, 52 (1960), 346.

(7) E. B. Kula and J. M. Dhosi: Trans. ASM, 52 (1960), 321.

(8) Y. Hosoi and K. E. Pinnow: Trans. ASM, 53 (1961), 591.

(9) V. F.Zackay, W. M. Justusson and D. J.Schmatz : Metal Progr., 80 (1961), Sept., 68.

(10) E.R. Petty, and H. O'Neill : J. Iron Steel Inst., 197 (1961), 141.

(11) V.F.Zackay, W. M. Justusson and D. J. Schmatz : Private Communication (Strengthening by Martensitic Transformation), Jan. 1, 1961.

(12) Y. Hosoi : Tetsu to Hagane (J. Iron Steel Inst. Japan), 48 (1962), 940.

(13) Y. Hosoi: ditto, 48 (1962), 1052.

(14) W. M. Justusson, and D. J. Schmatz: ASM Traps. Quart., 55 (1962), 640.

(15) A. J. McEvily Jr., and R.H. Bush : ASM Trans. Quart., 55 (1962), 654.

(16) Y. Hosoi: Tetsu to Hagane (J. Iron Steel Inst. Japán), 48 (1962), 1487. 
problems remain to require further precise observations and examinations. It is expected to find some evidences by transmission electron microscopy as already suggested by Justusson et al (14) and Radcliffe et $\mathrm{al}^{(17)}$. This paper reports on the results of some observations of the ausformed $\mathrm{Fe}-\mathrm{Ni}$ and $\mathrm{Fe}-$ $\mathrm{Ni}-\mathrm{C}$ martensites mainly by transmission electron microscopy.

\section{Experimental Procedure}

Specimens were prepared from electrolytic iron and electrolytic nickel by melting and casting in vacuum. They were hot forged and then cold rolled into 0.65 $\mathrm{mm}$-thick plates. Some of the plates were used as $\mathrm{Fe}-$ $\mathrm{Ni}$ specimens and others were carburized at $950^{\circ} \mathrm{C}$ for

to make $\mathrm{Fe}-\mathrm{Ni}-\mathrm{C}$ specimens. The chemical compositions of the $\mathrm{Fe}-\mathrm{Ni}$ and $\mathrm{Fe}-\mathrm{Ni}-\mathrm{C}$ specimens are shown in Table 1.

\begin{tabular}{|c|c|c|c|c|}
\hline Alloy & Ni $\%$ & C $\%$ & Fe \% & $\%$ ausformed \\
\hline $\mathrm{F} \theta-\mathrm{Ni}$ & 29.7 & 0.006 & bal. & $0 \%, 40 \%$ \\
\hline $\mathrm{Fe}-\mathrm{Ni}-\mathrm{C}$ & 29.7 & 0.420 & bal. & $0 \%, 24 \%, 30 \%$ \\
\hline
\end{tabular}

The specimens were austenitized at $900^{\circ} \mathrm{C}$ quenched in an oil bath at $200^{\circ} \mathrm{C}$. After being held in the bath for $2 \mathrm{~min}$, they were worked by rolling and air-cooled to room temperature. In the investigation by optical microscopy, no martensite was found in the Fe-Ni-C specimens, but an amount of martensite was observed in the $\mathrm{Fe}-\mathrm{Ni}$ specimens at room temperature. These specimens were then dipped in liquid nitrogen for $\mathbf{3 0} \mathrm{min}$. By this treatment, the transformation into martensite was almost completed in the $\mathrm{Fe}-\mathrm{Ni}$ specimens but about half in the Fe-Ni-C specimens. Specimens which had not been subjected to rolling were also used for reference, designating them $0 \%$-ausformed specimens.

The microhardness of these specimens was measured and the structures were observed by optical microscopy and transmission electron microscopy. Thin foils for the transmission electron microscopy were prepared by Bollmann's method in an electrolyte composed of phosphoric acid and chromic acid at $80^{\circ}$ C. The electron microscope used is a Hitachi HU-11, operated at $100 \mathrm{KV}$.

\section{Experimental Results and Considerations}

\section{Hardness}

Fig. 1 shows the results of hardness measurements. In the case of $500 \mathrm{~g}$-loading, the measurement was made irrespectively of the microstructure, while in the case of $50 \mathrm{~g}$-loading it was made for martensite and auste-

(17) S.V. Radcliffe and E. B. Kula : "Deformation, Transformation and Strength", presented at the Conference on Fundamentals of Deformation Processing. Sagamore, N.Y, Aug. 1962. nite separately. In $500 \mathrm{~g}$-loading, the $\mathrm{Fe}-\mathrm{Ni}$ specimen was scarcely hardened, but the $\mathrm{Fe}-\mathrm{Ni}-\mathrm{C}$ specimen was markedly hardened by ausforming. The hardness of austenite in the $\mathrm{Fe}-\mathrm{Ni}$ specimen was measured before.. deep-cooling in lquid nitrogen because after deep-
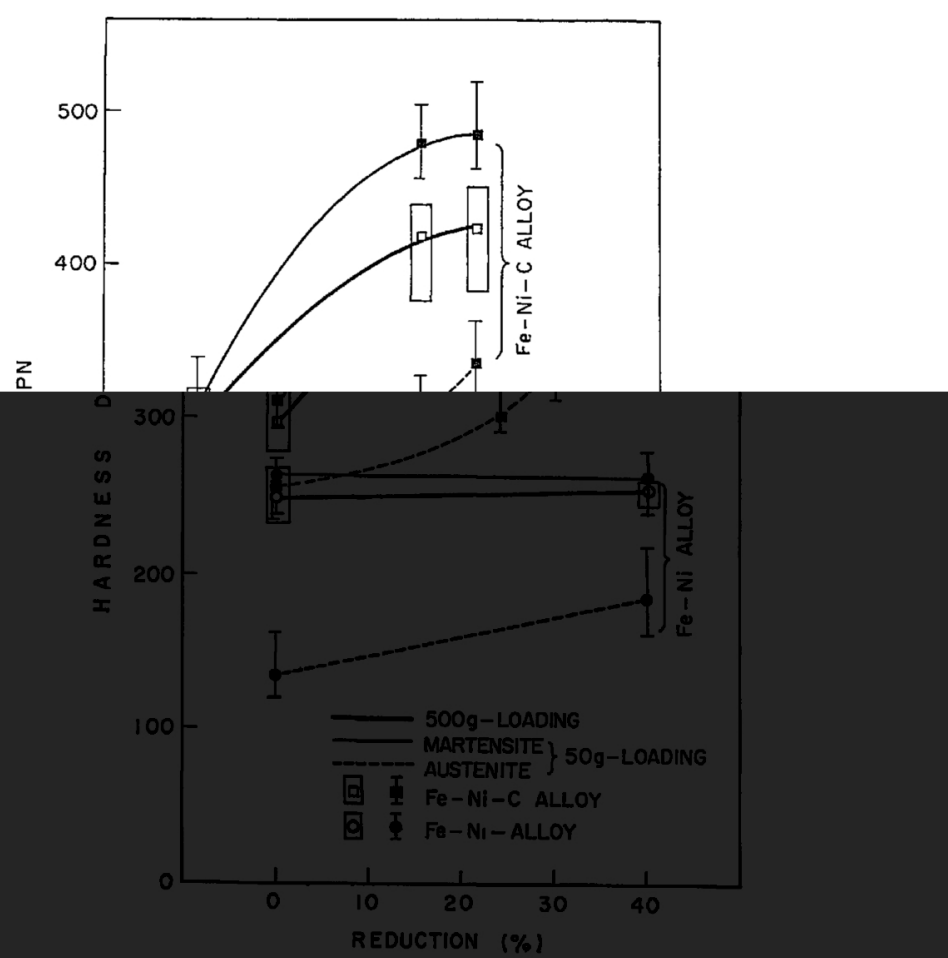

Fig. 1 Hardness of martensite and austenite in ausfor$\operatorname{med} \mathrm{Fe}-\mathrm{Ni}$ and $\mathrm{Fe}-\mathrm{Ni}-\mathrm{C}$ alloys measured by $50 \mathrm{~g}$-loading and hardness of the same alloys for $500 \mathrm{~g}$-loading. Each point-10 readings. Il represent spread.

cooling the austenite was markedly reduced in quantity, but in the Fe-Ni-C specimen it was measured for austenite retained after deep-cooling. In the $\mathrm{Fe}-\mathrm{Ni}$ specimen the austenite was hardened by straining, but the extent was smaller than that in the $\mathrm{Fe}-\mathrm{Ni}-\mathrm{C}$ specimen. The martensite in the $\mathrm{Fe}-\mathrm{Ni}$ specimen was scarcely hardened by ausforming. In the $\mathrm{Fe}-\mathrm{Ni}-\mathrm{C}$ specimen, however, not only the austenite but also the martensite was markedly hardened by ausforming. Thus, the effect of ausforming was clearly found in the Fe-Ni-C alloy, but not in the Fe-Ni alloy. It may, therefore, be considered that some amount of the carbon content is essential for the strengthening of steel by ausforming.

But, Justusson et al(14) have shown that the increment of yield strength of steel by ausforming does not depend on the carbon content. However, their experiments were carried out for a series of steel containing more than $0.3 \%$ carbon. The results can be explained that an excessive amount of carbon is not effective on the strengthening of steel by ausforming, although some amount of carbon is required to increase the strength by segregation to the dislocations and saturating them. A small amount of the carbon content may be sufficient to saturate the dislocations, depending upon the dislocation density which is high in the case of the ausformed specimen as shall be described later. 


\section{Optical microscopic structure}

Photo. 1 shows optical micrographs of the $\mathrm{Fe}-\mathrm{Ni}-\mathrm{C}$ specimens in the $0 \%$ - and $30 \%$-ausformed states after deep-cooling. Both of them have a lightening or zigzag shaped martensite. The structure of the $30 \%$-ausfor-

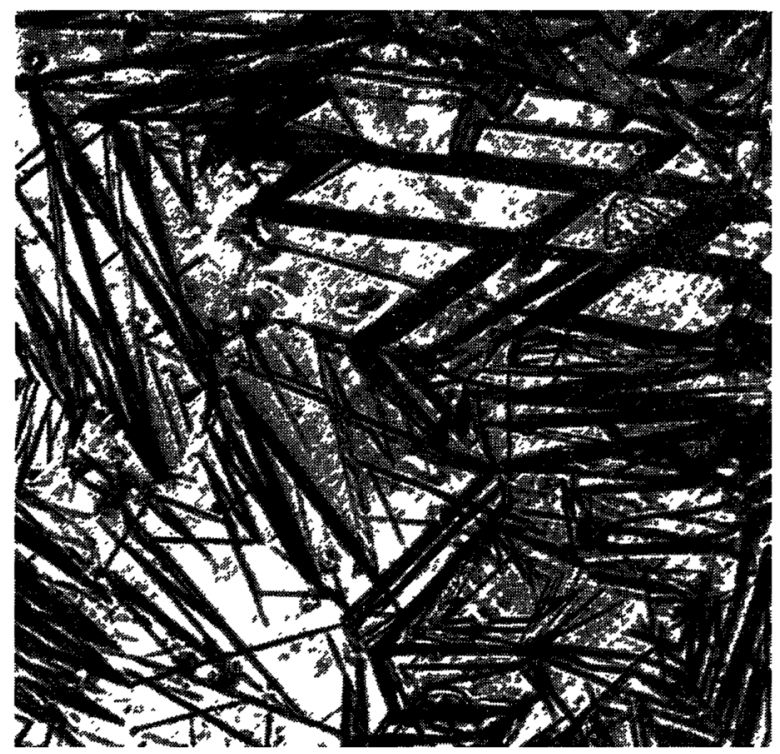

$\begin{array}{ccc}(\mathrm{A}) & \text { (B) } \\ \text { Photo. } 1 \text { Structures of }(\mathrm{A}) 0 \% \text { - and (B) } 30 \% \text {-ausformed } \mathrm{Fe}-\mathrm{Ni}-\mathrm{C} \text { alloys taken by an opticalmicroscope. }\end{array}$

ted by Nishiyama and Shimizu(18)(19) and by Kelly and Nutting (20)(21) to two kinds of crystals which had a twin relation to each other. The features of the structure in Photo. 2 are such that the fine paral. lel bands run through the whole martensite plate, and

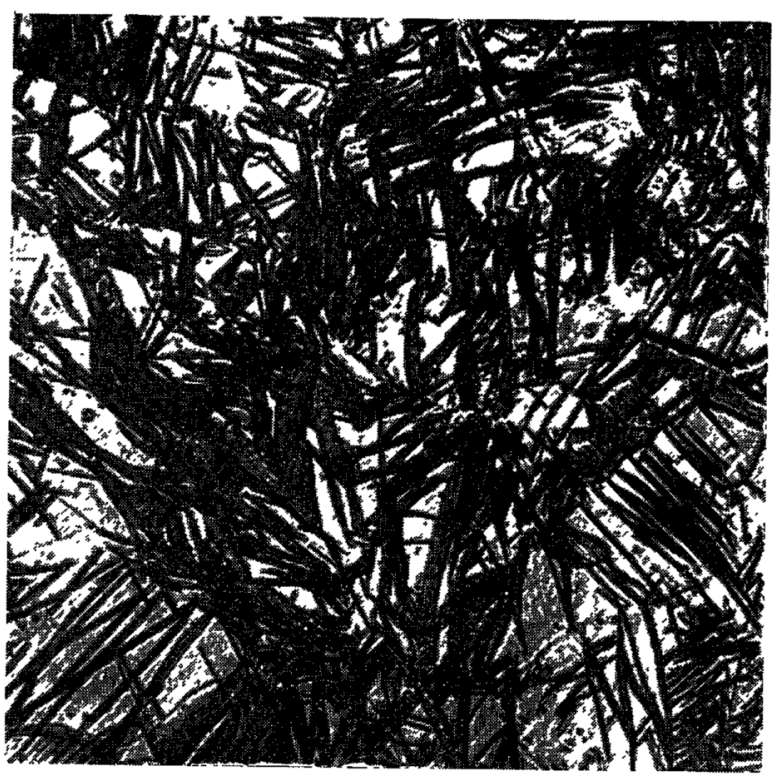

(B) $\times 200$, Etchant: $1 \%$ Nital.

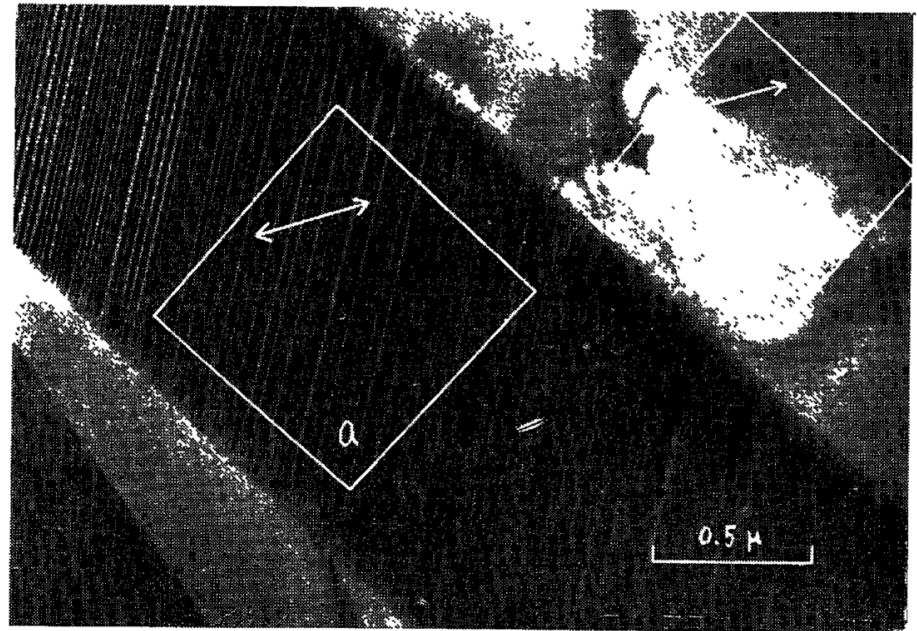

Photo. 2 Transmission electron microstructure of a $0 \%$-ausformed Fe-Ni-C alloy.

med specimen is, however, finer than that of the $0 \%$ ausformed, and the martensite plates are small, and warped, bent and kinked, while those in the $0 \%$ ausformed are large and straight.

The above facts are in agreement with those reported by several researchers. ${ }^{(4) \sim(7)(9)(11)(14)}$ Such a structure in the ausformed specimen may be produced due to the interaction of the martensite plate in growth with slip bands and deformation bands existing in the deformed austenite (11)(14).

\section{Structures observed by transmission ele- ctron microscopy}

Photo. 2 shows a transmission electron micrograph of martensite and retained austenite in the $0 \%$ ausformed $\mathrm{Fe}-\mathrm{Ni}-\mathrm{C}$ specimen. There are fine parallel bands having an interval of $100-400 \AA$ in the martensite. Such a structure of martensite has been attribu- that the shape of bands at the ends (interface between martensite and austenite) indicates them to be platelike. Furthermore, there are some lines and dark dotted images between the bands. They are explained as contour fringes and fine precipitates of carbide on the twin faults, respectively. The micrograph is very clear and dislocations in the martensite are hardly observed. The structure of austenite is smooth, and there are a few smooth contour fringes and dislocations.

The diffraction pattern of selected area (a) in the martensite in Photo. 2 is shown in Photo. 3. This pattern indicates that there are martensite crystals of

(18) Z. Nishiyama, and K. Shimizu: Acta Met., 7 (1959), 432.

(19) K. Shimizu: J. Phys. Soc. Japan, 17 (1962), 508.

(20) P. M. Kelly and J. Nutting : J. Iron Steel Inst., 197 (1961), 199.

(21) P. M. Kelly and J. Nutting: Proc. Roy. Soc., 259 (1960), 45. 
two kinds of orientations which have a twin relation to each other with respect to the $(2 \overline{1} 1)$ plane, and the fine bands in the structure of Photo. 2 are the trace of the twin faults. Photo. 4 shows the diffraction pattern of selected area (b) in austenite in Photo. 2. the plate are changed. It may therefore be expected that the martensite plates are bent and distorted at those barriers in the austenite, and frequently the growth no longler continues. Finally, high stresses of wide range are retained within and around the mar-

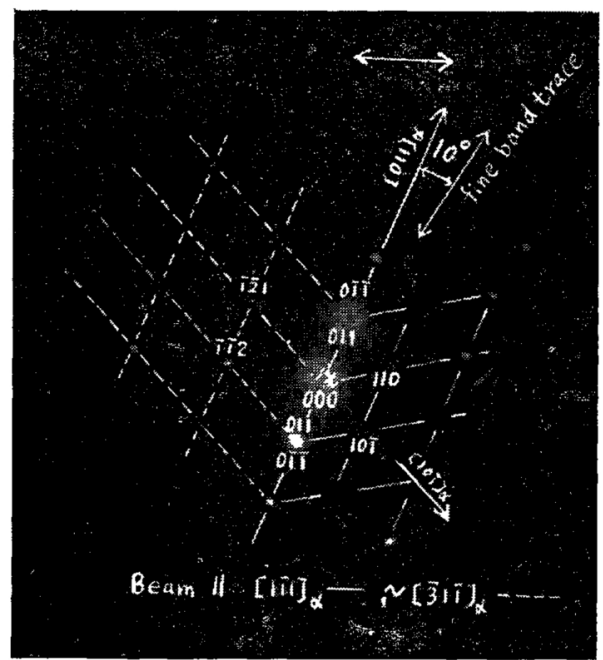

Photo. 3 Electron diffraction pattern of area (a) in Photo. 2.

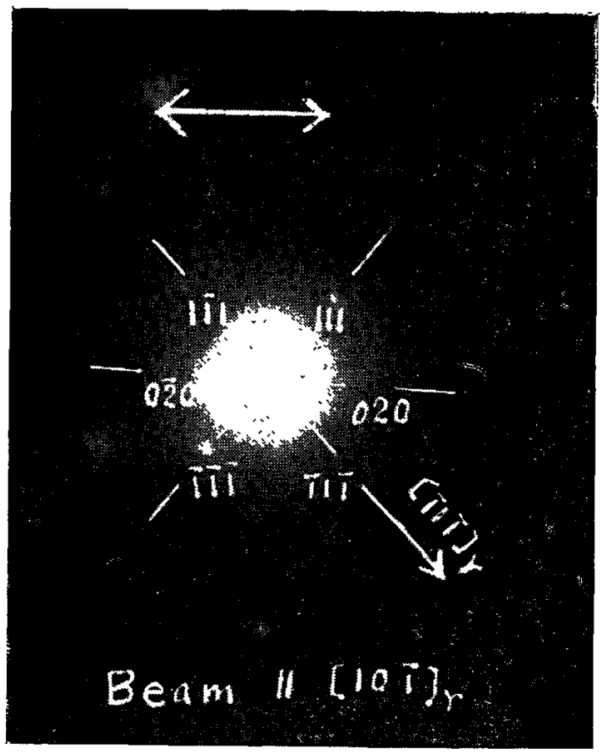

Photo. 4 Electron diffraction pattern of area (b) in Photo. 2.

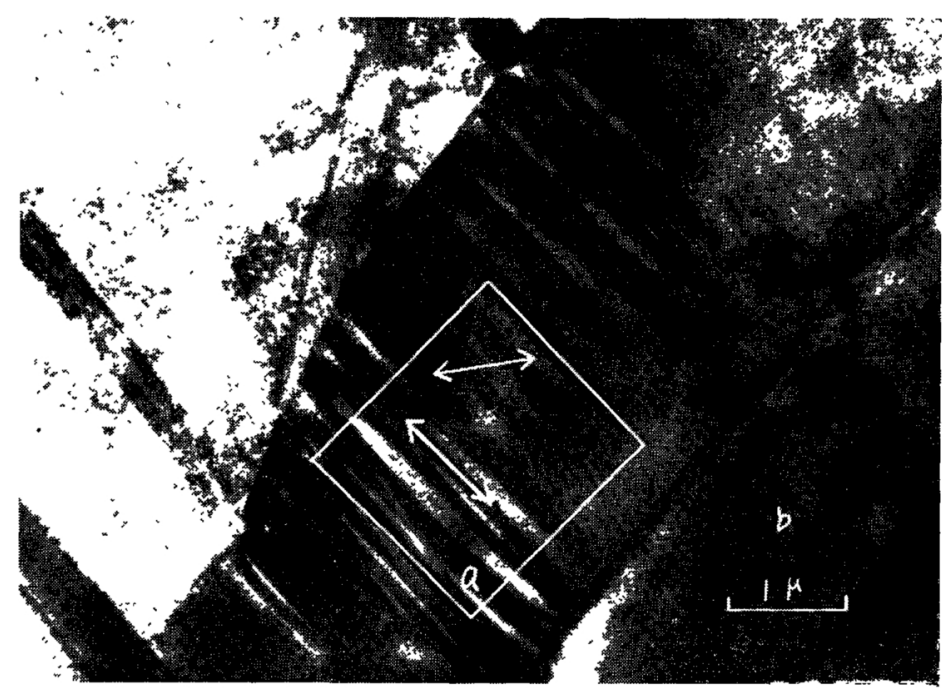

Photo. 5 Transmission electron microstructure of a 30\%-ausformed Fe-Ni-C alloy showing the broad bands in martensite.

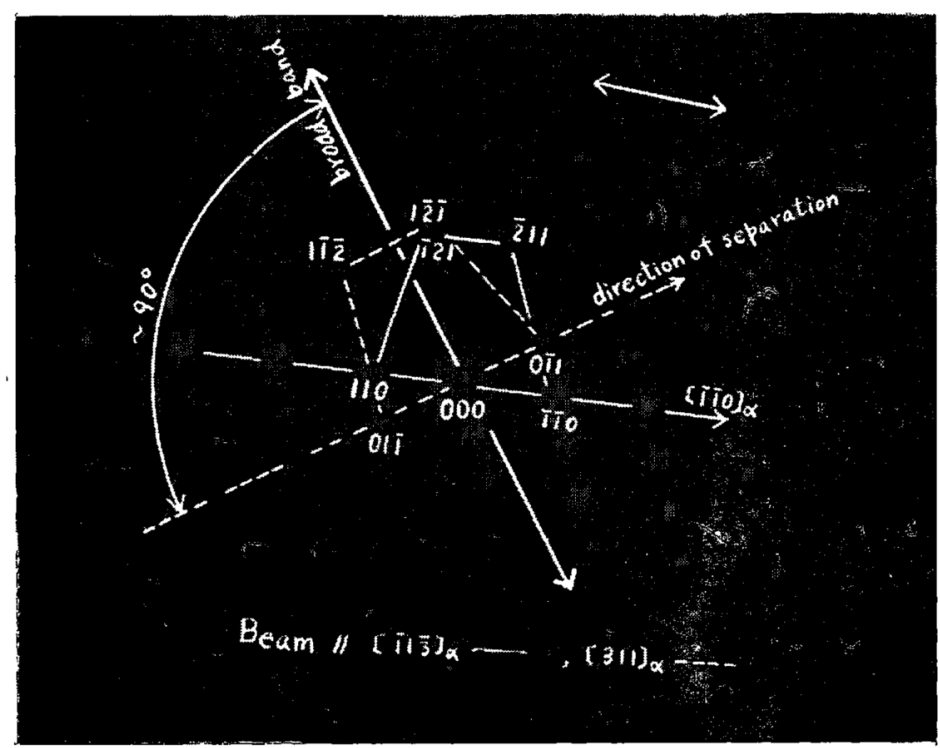

Photo. 6 Electron diffraction pattern of area (a) in Photo. 5.
It has been recognized that the habit plane of martensite is $\{259\}_{r}$ and that the lattice orientation relationship between austenite and martensite is approximately $(1 \overline{1} 1)_{a} / /(10 \overline{1})_{\tau},[10 \overline{1}]_{a} / /[\overline{1} 1 \overline{1}]_{\tau}$, which agree with those reported so far.

Photo. 5 shows an electron micrograph of the $30 \%$ ausformed $\mathrm{Fe}-\mathrm{Ni}-\mathrm{C}$ specimen. In the martensite, there are several diffused and broad lamellar bands. These bands are extinction contour fringes.

Zackay et al. (11) have reported the morphology of martensite formed from deformed austenite, as observed by optical microscopy. According to them, slip bands, deformation bands and sub-boundaries in the deformed austenite are semipermeable barriers to the passage of the martensite plate. When the martensite plate grows passing through the slip bands or deformation bands, the growth process and the shape of tensite plate, and the plate becomes finer. When the thin foil for transmission electron microscopy is made from a bulk material having such retained stresses, it would be bent locally by the stresses. In such a case, many extinction contour fringes can be observed in the micrograph. The fringes in Photo. 5: are the typical examples.

Photo. 6 shows an electron diffraction pattern of the ausformed martensite at the selected area of Photo. 5. The twinned pattern is also observed. Each of the diffraction spots located on the lower-left and the upper-right sides in Photo. 6 consist of two or three separate spots. The direction of separation. is approximately perpendicular to the direction of the broad bands in Photo. 5 . The separation is probably caused by the fact that the thin foil is bent wavily around the direction of the lamellar broad bands and 
hence the lattice is severely distorted.

The most important peculiarity of martensite in the ausformed specimen is that the image of the martensite is not clear as observed in Photo. 5. Such an image shows the existence of a cloudy distribution of dislocations at which extremely fine particles of carbide may precipitate. The high dislocation density in the ausformed martensite is made more clearly obser- ties of ausformed martensite.

4. Lattice orientation relationship between austenite and martensite in the ausformed Fe-Ni-C alloy

Photo. 8 shows a structure of the $30 \%$-ausformed $\mathrm{Fe}-\mathrm{Ni}-\mathrm{C}$ alloy. The electron diffraction patterns of selected area (a) (martensite) and (b) (austenite) in

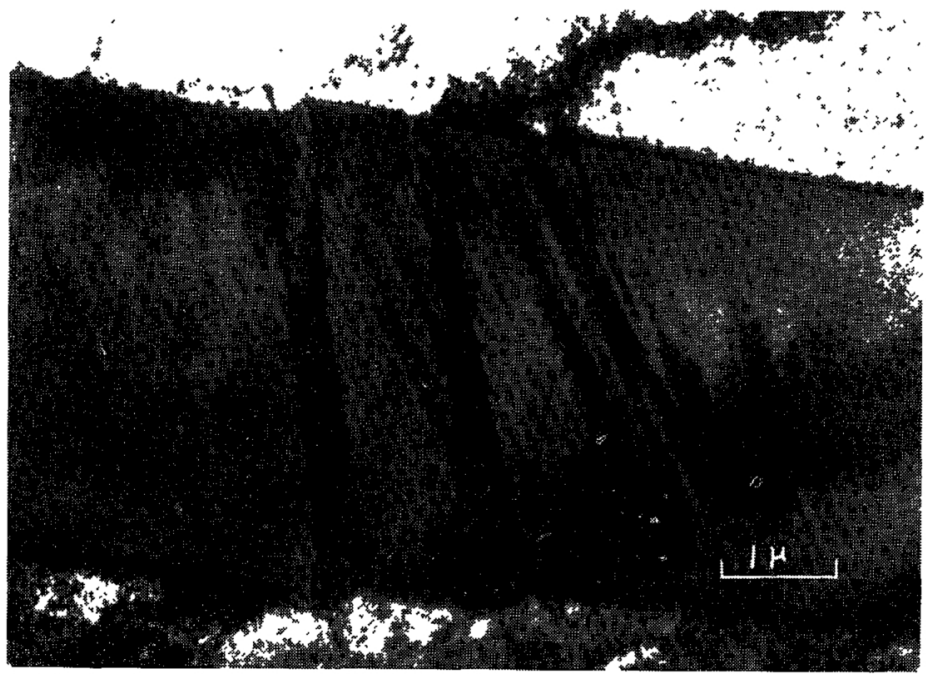

Photo. 7 Transmission electron microstructure of a $30 \%$-ausformed $\mathrm{Fe}-\mathrm{Ni}-\mathrm{C}$ alloy showing the kinking of martensite plate.

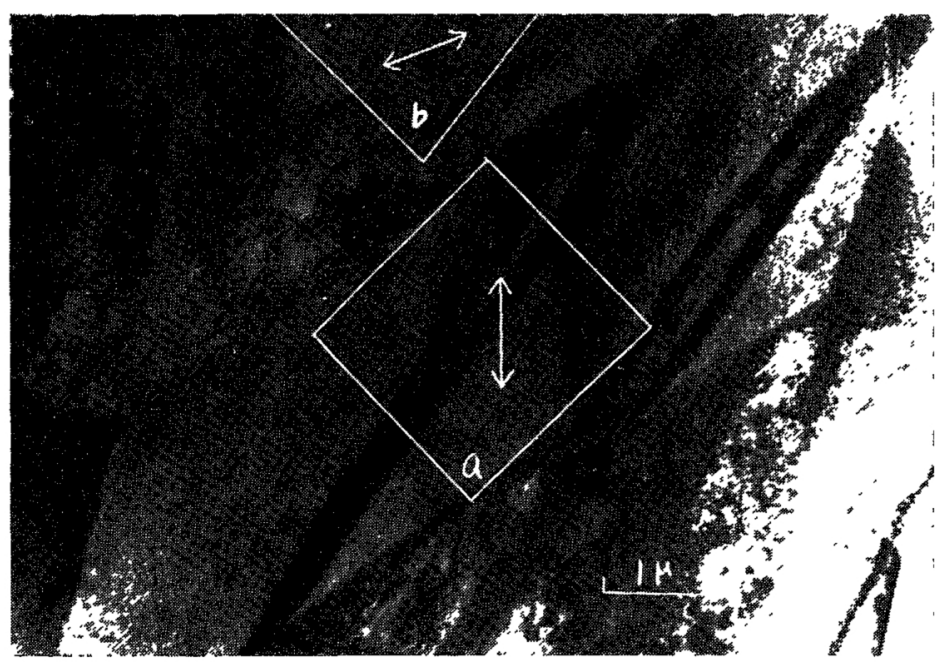

Photo. 8 Transmission electron microstructure of a $30 \%$ ausformed $\mathrm{Fe}-\mathrm{Ni}-\mathrm{C}$ alloy.

vable by tempering (22).

The twin faults are also observed in the ausformed martensite plate (b) in Photo. 5 in the same manner as in the unausfomed martensite. But; usually, it is difficult to observe the twin faults in the ausformed martensite because of hindrances of several images of dislocations, fringes and others.

A dense distribution of dislocations is observed in the austenite in Photo. 5. The austenite is evidently strain-hardened.

Photo. 7 is another electron micrograph of the 30 $\%$-ausformed $\mathrm{Fe}-\mathrm{Ni}-\mathrm{C}$ specimen. The martensite plate is kinked corresponding to the kinking seen in the optical micrograph. This is also one of the peculiari-

(22) I. Tamura, H. Yoshimura, M. Ibaraki and M. Tagaya ; to be published.
Photo. 8 are shown in (A) and (B) of Photo.9, respec. tively. The lattice orientation relationship between austenite and martensite is approximately $(111)_{\tau} / /$ $(011)_{a}$ and $[1 \overline{1} 0]_{r} / /[\overline{1} 11]_{a}$. Thus the usual relationship holds even in the ausformed state. Kula et al (23) have determined the preferred orientation of rolled austenite assuming that Nishiyama's relationship holds even in ausformed specimens, The results obtained from Photo. 9 prove their assumption to be correct.

\section{Consideration on the strengthening by ausforming}

According to Winchell et al( ${ }^{4)}$, the martensite even

(23) E. B. Kula and S. L. Lopata: Trans. AIME, 215 (1959), 980.

(24) P. G. Winchell and M. Cohen: ASM Trans. Quart., 55(1962), 437, and MIT Metallurgy Rept., 12(1961), No.4 the 5th paper. 
in the unausformed specimen can be gradually agehardened at room temperature due to segregation of carbon atoms mainly on the twin faults $(-2)$. In the ausformed martensite, there are a wide range internal stress and a cloudy distribution of dislocations. Since

(A)

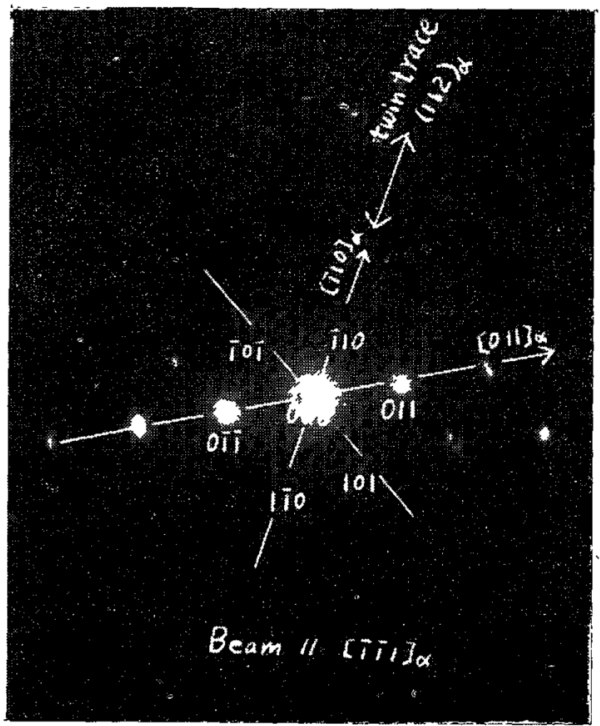

(B)

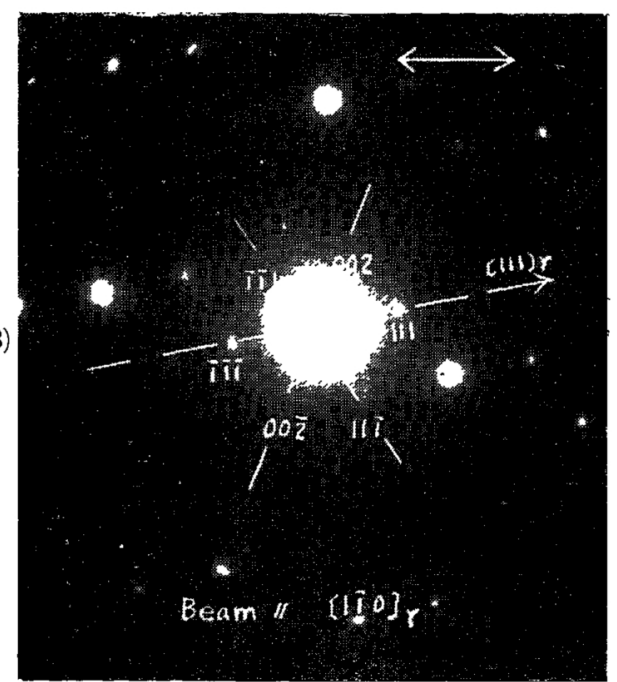

Photo. 9 Electron diffraction patterns of area (a) and (b) in Photo. 8.

the nucleation of carbide is enhanced by the presence of dense dislocations, the martensite of the ausformed specimen becomes a pre-precipitated state or an agehărdened state more steadily, and the precipitated carbide particles are finer and more closely dispersed than those in the unausformed. Furthermore, the martensite plate becomes finer and is bent and kinked by ausforming. Therefore, the martensite in the ausformed specimen is harder than that in the unausformed.

As for the origin of dislocations in the ausformed martensite, difficulty is encountered to decide whether the dislocations are inherited from the deformed austenite or they are produced in the martensite to accommodate the stress during or after martensite formation. But, the former might be able to explain the strengthening of steel by ausforming.

Generally, alloys hardened by precipitation or dispersion of fine particles are reduced in ductility, namely, elongation and reduction of area. Lower ductility in the technological sense means a large possibility for the fracture of material. When numerous dislocations are piled up at a few obstacles in the material during the tensile test, a large stress concentration occurs and the material is easily fractured with the resulting decrease in ductility. On the contrary, when few dislocations are piled up at numerous obstacles which are densely distributed over the material, the stress is not so much concentrated and the material does not become so brittle even in the hardened state.

The ausformed steel has fairly good ductility. (11) (14)(17) For this reason, it may be expected that in the ausformed steel there are some factors such as the fineness of martensite plates which reduce the stress concentration, together with the factors for strengthening of steel as described above.

\section{Summary}

The hardness and the structures of ausformed $\mathrm{Fe}$ $\mathrm{Ni}$ and $\mathrm{Fe}-\mathrm{Ni}-\mathrm{C}$ alloys have been examined. The results are summerized as follows :

(1) Some amount of the carbon content is essential for the strengthening' of steel by ausforming.

(2) The ausformed martensite is harder and finer than the unausformed, and is bent and kinked.

(3) In the ausformed martensite, densely distributed dislocations at which carbon atoms segregate are observed.

(4) A large internal stress of wide range are recognized in the ausformed martensite.

(5) Usual lattice orientation relationship between austenite and martensite holds good even in the ausformed specimen.

(6) The ausformed steel has a high strength due mainly to precipitation and/or dispersion of fine carbides on the dense dislocations, and has a fairly good ductility due to some factors such as the fineness of martensite plates which reduce stress concentration, together with the strengthening factors.

\section{Acknowledgement}

The authors wish to thank Prof. Z. Nishiyama and all the members of his laboratory, especially Dr. K. Shimizu and Dr. H.Fujita, for their valuable discussion, and thanks are also due to Mr. A. Koreeda for taking the electron micrographs. 